\title{
Band Pass Semi-Adaptive Digital Filters for Radar Applications
}

\author{
Pramil, Prateek, Parashuram
}

\begin{abstract}
This paper demonstrates the Digital semi Adaptive Filter which is applied to Radar signals to reduce the blast. Semi Adaptive filter has the strong anti-noise ability; it can also achieve accurate Radar Signal in a very noisy situation. The clatter removing application of the semi Adaptive Filter has been used in spectrum cleaning of the atmospheric radar signals. The object of this work is to plan and recital assessment of band pass Bartlett and chebyshev semi adaptive filters. This design used MATLAB and XILINX software's. FPGA hardware SPARTAN kit use for translates realistic research design. The simulation results indicate that Adaptive Filter has strong anti-noise ability for Radar. These works keeping the sampling frequency at $5 \mathrm{MHz}$ were compared and analyzed, optimized evaluated for 64 orders.
\end{abstract}

Index Terms - Digital filter, Field Programmable Gate Arrays (FPGA) MATLAB software and XILINX software, SPARTAN-3E, DSP Chips.

\section{INTRODUCTION}

$\mathrm{D}$ egradation can be reducing by using filtering method FIR, Adaptive filter. The target of a future Radar Signal enhancement algorithm should be a decrease of discarded surroundings noise. Each method has its own advantage and efficiency depend on the type of noise. In Radar, discarded noise use energy and deteriorates the target information of the signal there are a variety of method to reduce noise both analog and digital. Each method has its own advantages and efficiency is often dependent upon the type of noise. The noise suppression has application is virtually all field of communication (channel equalization, signal processing etc.) and other field In this paper our experiments on filtering technology. The output signal from the filter is compare with the desired signal which we want to obtained and find the best filter for noise diminution. After conclusion the adaptive filter is best than the FIR filter and adaptive filter to achieve the best performance of Radar Signal. This research mainly focuses on design efficient digital adaptive filters to abolish the noise source associated with the radar front end signal so as to get a noise free signal as output from the filter.

Revised Manuscript Received on February 05, 2020.

* Correspondence Author

Dr. Pramil, EC Department, RNTU, Bhopal, pramil327@gmail.com Dr. Prateek, EC Department, RNTU, Bhopal, pramil327@gmail.com Dr. Parashuram, EC Department, RNTU, Bhopal, pramil327@gmail.com

(C) The Authors. Published by Blue Eyes Intelligence Engineering and Sciences Publication (BEIESP). This is an open access article under the CC BY-NC-ND license (http://creativecommons.org/licenses/by-nc-nd/4.0/)

\section{PROPOSED METHODOLOGY}

\section{A.Software Design}

The proposed software design block diagram is exposed in Diagram.1. The following design procedure uses :

(i) Filter Design and coefficients fabrication matlab and Xilinx software tool is used.

(ii) Design band pass 380-400 KHz semi adaptive Bartlett and Chebyshev Finite Interval Response digital filter xilinx software tool was used.

(iii) $\quad 5 \mathrm{MHz}$ sampling frequency use for derived Filter response of order 63 .

(iv) MATLAB software use for manipulative of SNR

MATLAB tool use to generate particular digital filter response and coefficients for VHDL implemented design. Digital filter drawing can be conceded out often selecting diverse choice available in apparatus for creation of essential coefficients for the particular filter from the $\mathrm{C}$ header option of the matlab tool. VHDL file use $\mathrm{C}$ header files for designing.

\section{B.Hardware Design}

SPARTA-3E for translate software design for the realistic effort. Digital storage oscilloscope displays the input and output. The following realistic design steps were carried out. The DIP switches, SPARTAN Logic kit using for circuit design.

(i) Design band pass semi adaptive filter for $380-400 \mathrm{KHz}$ Bartlett and Chebyshev type Finite Interval Response in FPGA kit.

(ii) DIP switches use for selecting different grouping such as sampling rates, frequency of the filter and input signal.

(iii) Translation and restoration of samples using 16 bit A/D and D/A converters.

(iv) AWGN noise mixed signal was passed through semi adaptive band pass filters for the frequency 380-400 KHz.

Four DIP switches use for filter coefficients. 2 DIP switches for $\mathrm{I} / \mathrm{O}$ and two selecting sampling rate. 


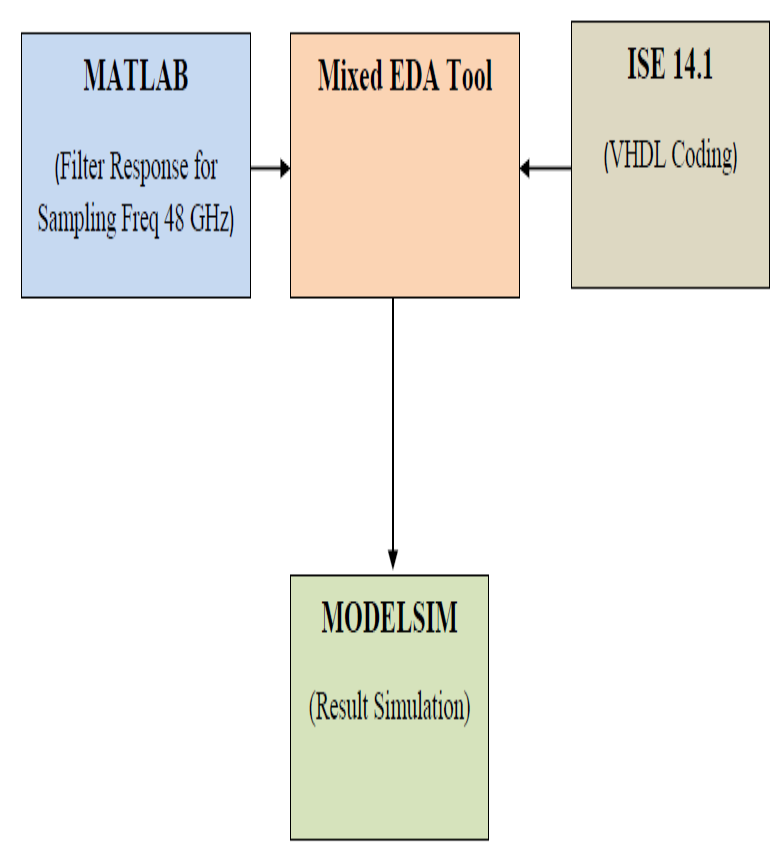

Figure 1. Block diagram of software Design

\section{RESULTS AND DISCUSSION}

Bartlett and Chebyshev digital band pass fir filters frequency responses are as shown in figures 2 and 3 respectively. Digital Bartlett and Chebyshev band pass FIR filters pass test signal of $390 \mathrm{KHz}$ display in Figures 2 and 3 respectively. Bartlett and Chebyshev types of filters SNR enhancement display in figures 4 and 5 . The input signal, test signal with noise and filtered output signals shown figure 6 obtained from realistic set up using FPGA kit pragmatic in a two channel digital oscilloscope.

Chebyshev filter observations specify that clatter is not concealed 100 percent and some clatter components seen in output and far lesser to Bartlett digital filter of the similar design.

In Bartlett types design evidently seen that clatter is concealed and the test signal has been passed. Bartlett type's software and hardware design response display in figures 4 and 6 correspondingly. Practically \& the simulated filter Bartlett filter have rejected the noise. Two channel digital oscilloscopes observed Bartlett $\mathrm{i} / \mathrm{p}$ signal and o/p signal which is using FPGA kit.

When compare Bartlett with Chebyshev of design. Chebyshev circuit original signal is totally mixed with noise indicating lowliness.

Bartlett digital filter SNR improvement factors is 7.76 $\mathrm{dB}$ and Chebyshev digital filter SNR enhancement factors is $7.56 \mathrm{~dB}$ which is shown in figures 4 and 5 . SNR enhancement superiority of Bartlett digital filter is apparent from the similar design.

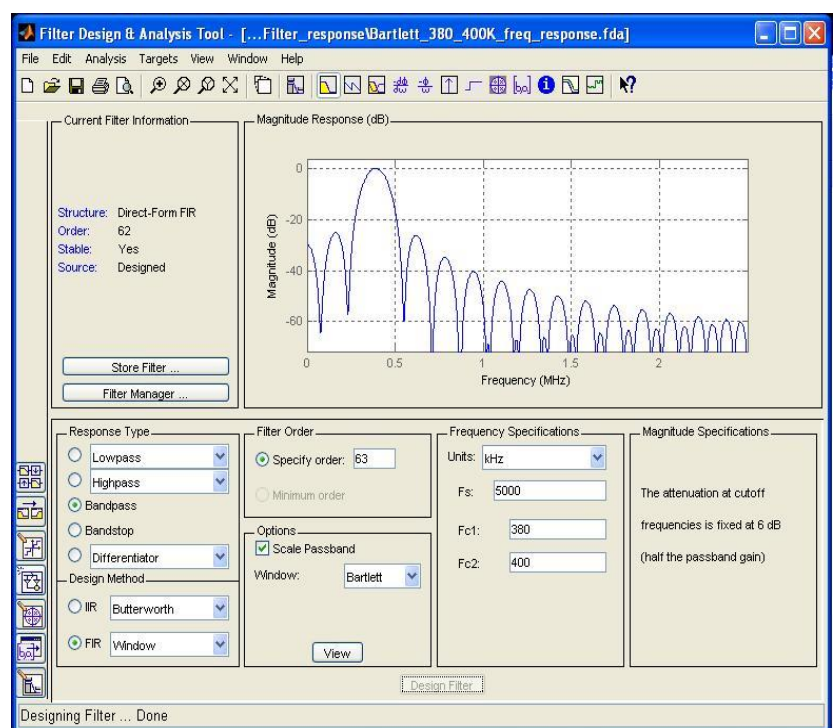

Figure 2 Software base Bartlett frequency Response

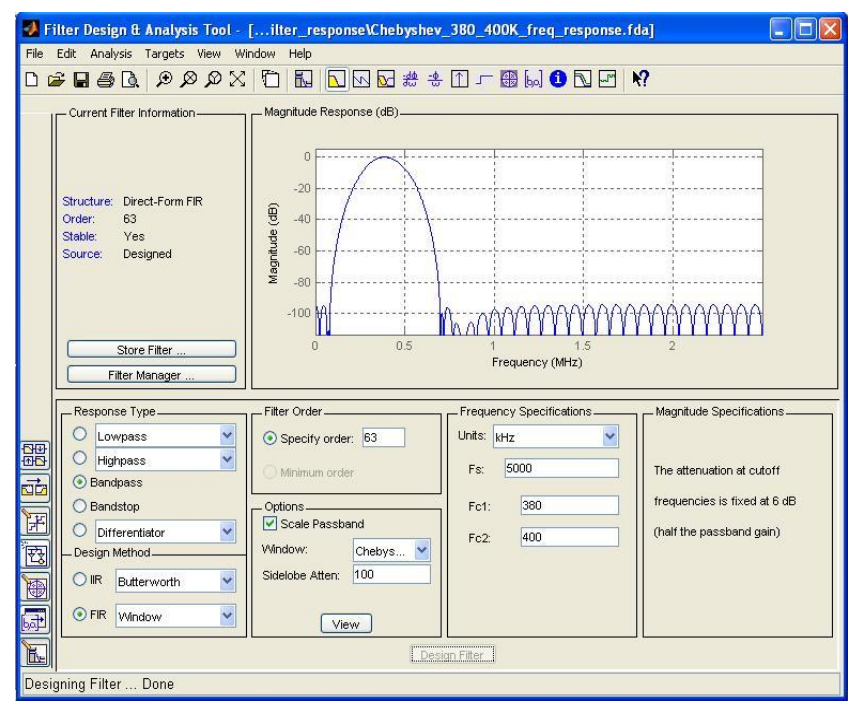

Figure 3. Software Base Chebyshev Frequency Response

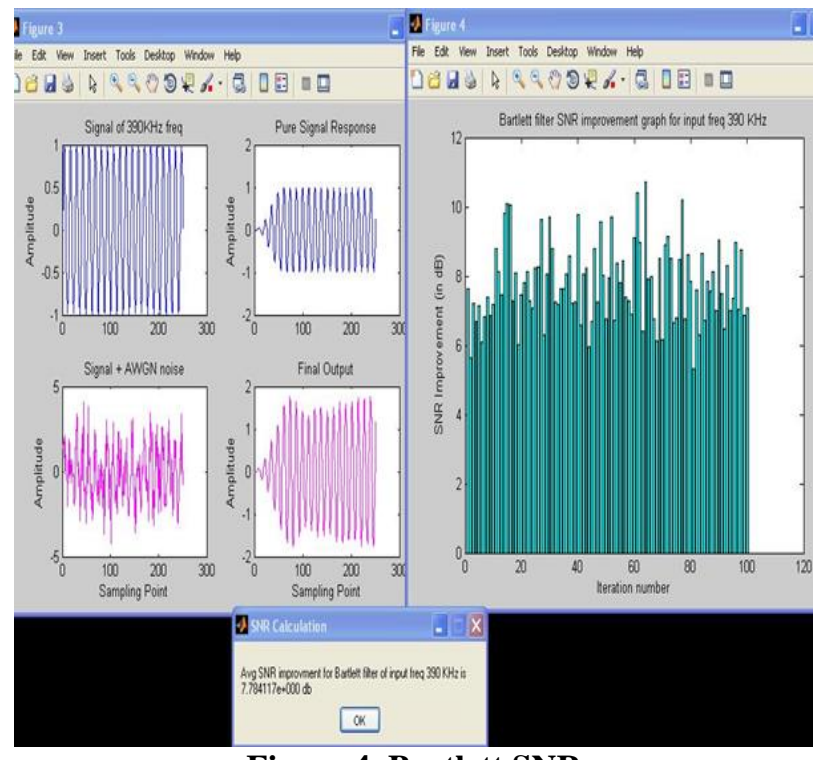

Figure 4. Bartlett SNR

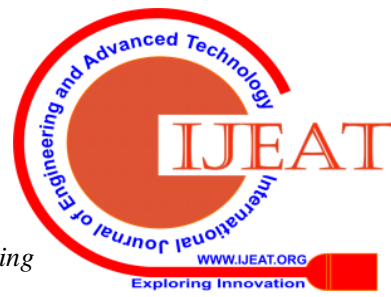




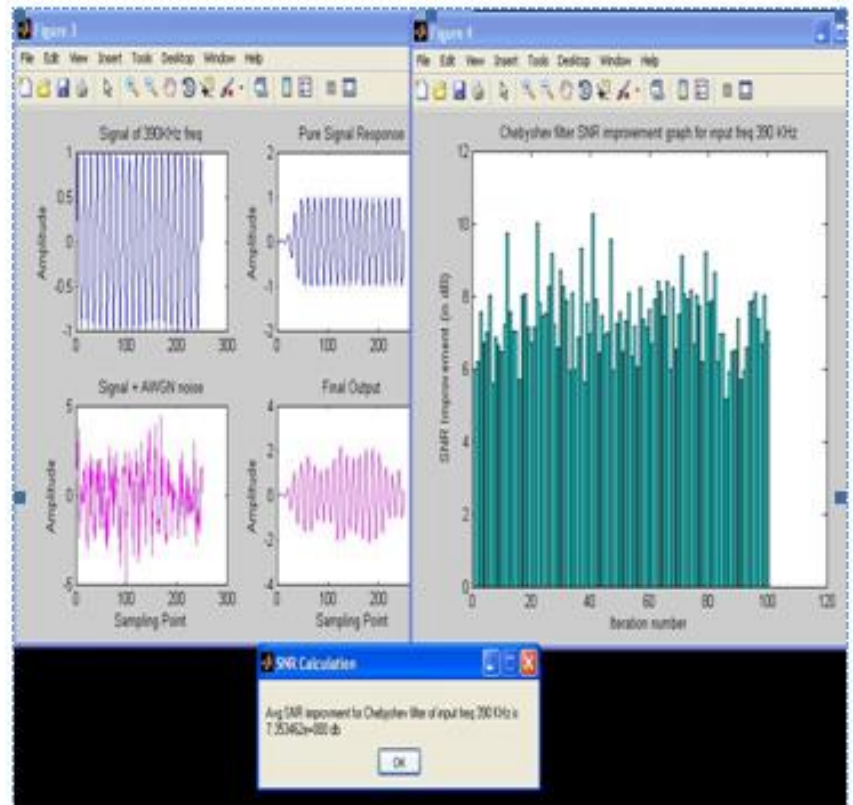

Figure 5. Chebyshev SNR

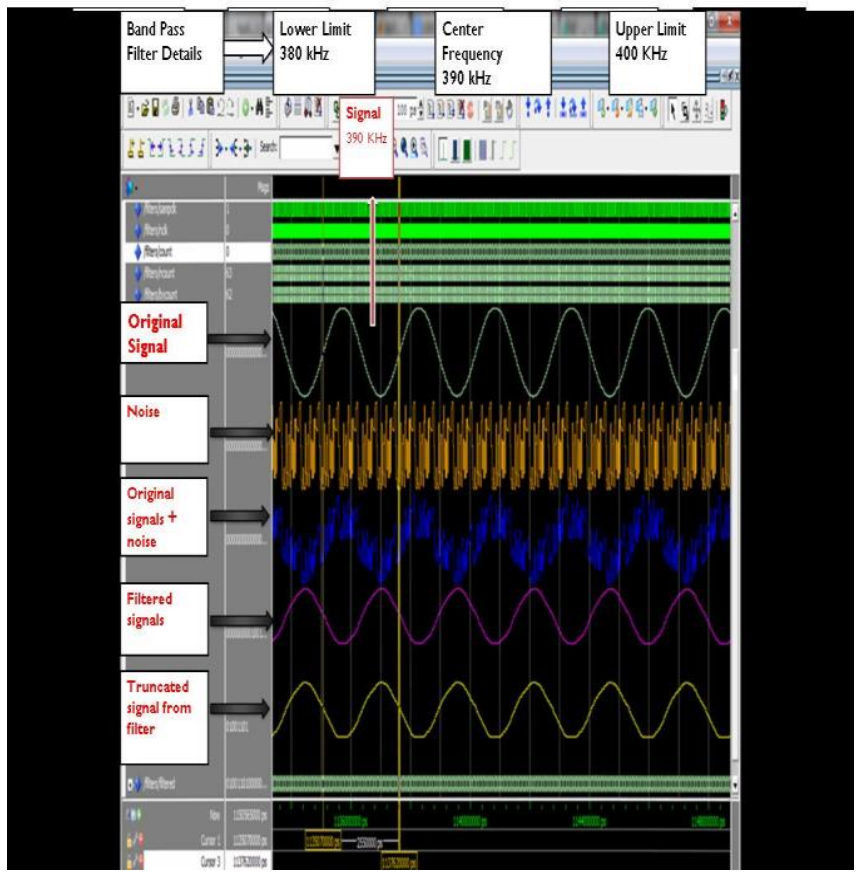

Figure 6. Hardware Base Response

\section{CONCLUSION}

Chebyshev and Bartlett FIR band pass 380-400 KHz semi adaptive digital filters design using FPGA kit along with 7 segment display for a sampling frequency of $5 \mathrm{MHz}$ and Analog to Digital \& Digital to Analog converters, DIP switches for successfully translated from XILINX and MATLAB software's based design. The hypothetical and realistic filter design reaction was effectively obtained for the designed frequency of $390 \mathrm{KHz}$. The supremacy presentation of Bartlett above Chebyshev of filter is clearly pragmatic from both kind of design with software \& hardware logically from the same designs.

Bartlett type of filter signal to Noise Ratio enhancement factor of $7.76 \mathrm{~dB}$ acquire is superior value low frequency band pass semi adaptive filter. Bartlett digital filters are appropriate for low frequency Radar uses to give the preferred target response and moderate arbitrary noise levels.
In this Paper design a digital filters for radar applications which work in low frequency for the purpose of deep sea bed are suitably demonstrated.

\section{FUTURE SCOPE}

This semi adaptive filter design is carried out for low frequency radar application such as deep detection inside the earth. Same approach can be used for high frequency radar employed for imagery mission.

\section{REFERENCES}

1. Lawrence R. Rabiner and Bernard Gold, " Theory and Applications of Digital Signal Processing”, Prentice Hall, INC

2. Alan V. Oppenheim, "Applications of Digital Signal Processing", Prentice Hall, INC

3. M, Hutson, "Acoustic echo cancellation using DSP", The School of Information Technology and Electrical Engineering, The University of Queensland, November 2003.

4. Haykin S.: "Adaptive filter theory", Printice-Hall, Englewood Cliffs, (N.J.) 1996.

5. Rafid Ahmed Khalil "Adaptive Filter Application in Echo Cancellation System and Implementation using FPGA" Al-Rafidain Engineering Vol.16 No.5 Dec. 2008

6. A. D. Whalen, Detection of Signals in Noise, Academic Press. Inc., Orlando, Florida, 1971.

7. N P Rallapalliand S Sharma, "Simulation of Adaptive Filter for Hybrid Echo Cancellation” ISSN: 0019-6339 vol.45 no.4 February 2009.

8. Curlander, J. C. and R. N. McDounough, Synthetic Aperture Radar, Systems and Signal Processing, John Wiley \& Sons, New York, 1991.

9. U. Maser, L. Banbse, "Digital Signal Processing with Field Programmable Gate Arrays",International Signal Processing Conference, March 28, 2006, Dallas Texas.

10. Ahmed Elhossini, Shawki Areibi, Robert Dony, "An FPGA Implementation of the LMS Adaptive Filter for Audio Processing" University of Guelph September 2006

11.Nitish V. Thakor, Yi-Sheng Zhu, “Applications of Adaptive Filtering to ECG Analysis: Noise Cancellation and Arrhythmia Detection” IEEE Transactions on Biomedical Engineering. 18(8). August 1997.

\section{AUTHORS PROFILE}

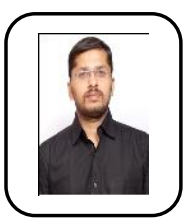

Dr. Pramil obtained his B.E. in Electronics \& communication engineering from Rajiv Gandhi Proudyogiki Vishwavidyalaya, Bhopal, India in 2006 and M.Tech. Degree in Microelectronics \& VLSI Design from S.G.S.I.T.S. Indore, India in 2010..He did his Ph.D.in EC from RNTU Bhopal in 2018, He is Member of IFERP.

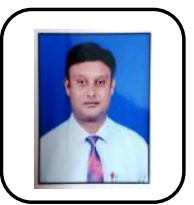

Dr. Prateek received his Master of Technology from the Department of Electrical Engineering, IIT, Kharagpur (India) and Ph.D from Rabindranath Tagore University, Bhopal. He is currently working as an Associate Professor in the Department of Electrical \& Electronics Engineering in Bansal College of Engineering, Mandideep. He is also a senior member of IETE and IFERP. His research interests include Renewable Energy, Instrumentation \& Control, wireless communication and power system stability.

Dr. Parashuram is a post graduate from IIT- Kanpur (India) and he did his $\mathrm{Ph} \mathrm{D}$ in Electronics and Communication from UIT RGPV, Bhopal. He has served in Indian Air Force as commissioned officer for 25 yrs, and nine yrs, as a technocrat academician in reputed Engg. Institutes. He is an entrepreneur who has many project patents under his name. He is a fellow of IETE. 